\title{
Curbing publicly-funded family planning services in Iran: who is affected?
}

\author{
Amir Erfani
}

Professor, Department of Sociology, Nipissing University, North Bay, Ontario, Canada

\section{Correspondence to Professor Amir Erfani, Department of Sociology, Nipissing University, 100 College Drive, Box 5002, North Bay, Ontario, Canada P1B 8L7; amire@nipissingu.ca}

Received 29 October 2015 Revised 24 August 2016 Accepted 17 November 2016

\section{CLlinked}

- http://dx.doi.org/10.1136/ jfprhc-2016-101679

\section{CrossMark}

To cite: Erfani A. J Fam Plann Reprod Health Care 2017:43:37-43.

\begin{abstract}
Objective In response to a persistent low fertility rate in the country, the Supreme Leader of Iran in 2012 called for the shift to pronatalist population policies. Consequently, Iran's Parliament proposed a bill to curb the provision of contraceptive knowledge and services as a solution to raising the country's low fertility rate. This study aimed to investigate which groups of women will be adversely affected if the provision of subsidised contraceptive methods [i.e. sterilisation, intrauterine device (IUD) and injections] is curbed.
\end{abstract}

Methods This study used recent data from the 2014 Tehran Survey of Fertility $(n=3012)$ conducted among a representative sample of 3012 married women of reproductive age, and used multinomial logistic regression analysis to identify women with a higher likelihood of using government-funded contraceptive methods.

Results Currently $82 \%$ of married women living in Tehran use a contraceptive method. The use of long-acting contraception, namely sterilisation and IUDs, declined from $34 \%$ in 2000 to $20 \%$ in 2014 , and the prevalence of male methods (withdrawal and condoms) increased from 33\% to $55 \%$ in the same period. Multivariate results showed that women who have a large number of children, want no more children, live in poor districts, and have low education are more likely to use long-acting contraceptive methods than withdrawal and condoms.

Conclusions Women of low socioeconomic status who want to stop childbearing are the most vulnerable subgroups of the population if the publicly-funded family planning services are curbed.

\section{INTRODUCTION}

Iran has experienced an extraordinary fertility decline in recent decades. The country's total fertility rate (TFR), which rose slightly to 7.1 children per woman by 1986 , dropped to 4.9 children in

\section{Key message points}

- Tubectomy and the intrauterine device are the most prevalent long-acting modern contraceptive methods in Tehran, Iran.

- The long-acting methods are mainly used by poor and less well-educated women who have a larger number of children and want to stop childbearing.

- Any limitation on the provision of publicly-funded family planning services is likely to jeopardise the health of women of low socioeconomic status.

1991 and then reached a replacement level of 2.1 children in 2000, and a below-replacement level of 1.8 children per woman in $2011 .^{1-3}$ It has been estimated that $61 \%$ of the rapid decline in the period fertility rate during one decade is attributed to a sharp increase in deliberate marital fertility control through a rise in the use of family planning services, delivered freely through 17000 rural health houses and centres and urban health posts and centres. ${ }^{2}$ Through the new family planning programme a full choice of contraceptives, including female and male sterilisation, intrauterine devices (IUDs), the pill, condoms, implants and injectables, has been made available to all rural and urban married women. Iran's family planning programme has been recognised by domestic and international observers as one of the most successful in the world, and particularly in the Middle East. $^{4-7}$

Over the past decade, however, the fertility rate has remained low in Iran, 
where the TFR rate in 26 out of 31 provinces has fallen below the replacement level of 2.1, and six provinces, including Tehran, have a rate less than 1.5 children. ${ }^{8}$ The persistent low fertility has become an increasing concern for Iranian leaders, as it will lead to a rapidly aging population, a declining labour force, and a smaller overall population. As a result, increasing attention has been paid to policies that focus on raising fertility rates so that a larger number of younger, productive members of the population will be available to balance the increasing number of older people and thus promote economic development. For example, in 2012 the Supreme Leader of Iran called for an end to any population control policies and programmes in the country. ${ }^{9}$ Following this call, the legislative organisations proposed bills to eliminate the only family planning course in the postsecondary curriculum ${ }^{10}$ and ban surgical sterilisations for population control, ${ }^{11}$ and the then government eliminated funding for population control programmes ${ }^{12}$ in the hope of raising the low fertility rate.

In reaction to these pronatalist actions, this study aimed to investigate which subgroups of the population are likely to be adversely affected if the provision of family planning services is limited. Recent data from a large-scale fertility survey conducted in the capital city of Tehran are used to answer this question. First, to put the analysis into context, recent developments in Iran's population policies, targeting the provision of family planning services, will be briefly described.

\section{RECENT POPULATION POLICY DEVELOPMENTS IN IRAN}

The population policies of Iran have been formulated and legislated as part of a 5-year Socio-Economic and Cultural Development Program law (SECDP). In the first SECDP law, legislated by the Islamic Parliament of Iran (Majles) on 31 January 1990, population policy goals were set at reducing the TFR from 6.4 children per woman in 1986 to 4.0 in 2011, and reducing the rate of the natural increase in population from $3.2 \%$ to $2.3 \%$ within the same period. ${ }^{13}$ However, evidence from national censuses and demographic surveys showed that Iran surpassed these population policy goals within less than a decade after the approval of the law. In fact, the TFR dropped to 2.1 children in 2000 and 1.8 children in 2011, and the rate of natural increase in population plunged to $1.5 \%$ and $1.3 \%$ in 1996 and 2011, respectively. ${ }^{2}{ }^{3}$ Such unprecedented declines in fertility and population growth rate created a fear of population decline among Iranian leaders, particularly the conservative figures who viewed declining population as a threat to national security. Consequently, they began to speak about a need for a shift from an antinatalist to a pronatalist population policy.
The recent debate on rising population in the country can be traced back to the former President Ahmadinejad, who frequently spoke about the need to prevent population decline by encouraging families to have more than two children. As an example, in March 2011 (the Iranian New Year) he announced that the government would grant a one-time cash incentive of one million Toman (equivalent to an average monthly salary) and a monthly payment of 100000 Toman to any child born in that year, a promise which has never been fulfilled. ${ }^{14}$ However, his pronatalist debates and slogans paved the way for the Leader to officially announce the end of the population control policy legislated in 1989.

In a speech given to public citizens in September 2012, Iran's Supreme Leader, Ayatollah Ali Khamenei, stated that "one of the mistakes that we [state officials] made (I myself also share in making this mistake), was that the population control must have been stopped from the mid-1990s and afterward, though the population control policy was good at the time it was legislated". $9 \mathrm{He}$ added, "If our population follows the current trends, we will have an aging country. So, families and young population should increase their reproduction". Then, he added that "the antinatalist policy must be put to an end".

Subsequently, the then Health Minister, Dr Marzieh Dastjerdi, declared that "the former population control policy has been removed and is no longer funded by the government, but we have asked the government to fund a new population program, known as 'Reproductive Health', with the amount of 190 billion Rials that fosters maternal and child health and deals with infertility". ${ }^{12}$ Later, she clarified that "the production, supply, and delivery of contraceptive methods continues as before, but we have only changed the direction of family planning toward reproductive health, focusing on proper birth spacing, maternal and child health, nutrition of healthy infants and children, and curing infertility". ${ }^{15}$ According to the then Director General of Family Health in the Ministry of Health, the new reproductive health programme will continue delivering publicly-funded family planning services and training to women living in regions with fertility rates at or above the replacement level to prevent unintended pregnancies, and to poor women and those who have high sexual and reproductive health risks. However, women who live in low fertility settings will not be entitled to free contraceptive services, as before, but they will be trained and informed about proper birth spacing, and healthy childbearing before, during, and after pregnancy. ${ }^{16}$

Though the government adopted a co-operative approach to women's reproductive needs, legislative organisations attempted to curb access to family planning services and knowledge, with the intention of raising fertility. For instance, the Supreme Council of 
the Cultural Revolution approved the removal of the 'Population and Family Planning' course from the post-secondary curriculum, and replaced it with a new course entitled 'Knowledge of Family and Population'. Therefore, since September 2013, university and college students have been taking the new course that focuses on marriage and family formation, spousal emotional relationships, and childbearing and rearing rather than sexual and reproductive health risks and contraceptive methods that was taught to students taking the former course. ${ }^{10}$ Moreover, the Parliament of Iran proposed Bill 446 in 2014 that bans any medical surgeries aiming to permanently prevent fertility, except in cases where a pregnancy presents a risk to women's physical and mental health. According to this bill, medical practitioners who defy this law will be fined. ${ }^{11}$

Such political turmoil surrounding the new evolving pronatalist population policy continued until the Leader, Ayatollah Ali Khamenei, officially announced 14 general policies on population with the purpose of making up for population decreases in recent years. ${ }^{17}$ According to two of these 14 policies, maternal and child health cannot be compromised by any pronatalist decision-making and programmes. This is why the Guardian Council of Iran returned Bill 446 to the Parliament for further revisions as it was seen to be inconsistent with the policies stated by the Leader. Since the bill is still alive and under review in Parliament, and there is the potential for proposing similar bills in the future, this study aimed to answer the question: If the provision of publicly-funded contraceptive methods, especially vasectomy, tubectomy and IUDs that are delivered by healthcare practitioners are limited, which groups of women are most likely to be at risk of unwanted pregnancies and therefore seek clandestine abortions, leading to maternal morbidity and mortality? Currently the government delivers free contraceptive methods, including sterilisation, IUDs, injections, pills and condoms, to vulnerable women, including those who are living in deprived settings with a large number of children and those who will risk their health and their fetus if they were to become pregnant. ${ }^{18}$ Only pills and condoms are additionally accessible via drugstores at an affordable price for the majority of the population.

\section{DATA AND METHODS}

This study used data from the 2014 Tehran Survey of Fertility, designed by the author and administered face-to-face, by a team of female interviewers trained by the author, among a representative sample of 3012 married women aged 15-49 years residing in Tehran's 22 residential districts. A wide range of data was collected by the survey, including complete histories of live births, contraceptive use, and induced abortions. The samples were selected by the author based on a three-stage stratified cluster random sampling design.
In the first stage, enumeration areas were selected in each residential district, and in the second stage residential clusters were chosen in each selected enumeration area. The selections in both stages were done based on the probability proportion to population size. The sampling frame for the selection of enumeration areas and residential clusters was taken from the 2011 Census of Iran. In the third stage, 15 households were selected in each cluster by a systematic random sampling method. From each selected household one eligible woman was then asked to participate in the survey. The study sample is limited to the 2461 women who reported using a contraceptive method during their interview. Analyses were adjusted for the survey sampling design using svy syntax in Stata software. The survey was granted ethical approval by Nipissing University's Research Ethics Board in June 2012.

To address the study's research question, we examined women's contraceptive use by method according to their socioeconomic and demographic characteristics. The dependent variable, therefore, was contraceptive method use in three categories: (1) long-acting modern methods, including vasectomy, tubectomy, IUDs and injections; (2) contraceptive pills and (3) withdrawal and condoms. The rationale for this classification is two-fold. First, the methods in the first group are publicly funded and they are delivered to women by public healthcare practitioners, while pills and condoms, as two other funded methods, can be obtained from drugstores at affordable prices by the majority of the population. Second, methods with similar user profiles, as shown in Table 1, were grouped into the same category. Women's socioeconomic status was measured by education and residential districts, where residents in the northern districts of Tehran are generally wealthier and more educated, and hold more modern attitudes regarding family formation and childbearing, while women living in the southern districts generally are of lower socioeconomic status.

Bivariate analyses were employed to describe women's contraceptive method use by their characteristics. Also, multinomial logistic regression models were used to identify women who were at elevated risk of relying on long-acting contraceptive methods rather than male contraception, namely condoms and withdrawal.

\section{RESULTS}

\section{Trend of contraceptive use by methods}

Figure 1 shows the trend of contraceptive use in Tehran. Over the last decade, while men's participation in contraceptive use increased, the use of female methods decreased. Specifically, $20 \%$ of married women in 2014 used long-acting contraceptive methods (i.e. vasectomy, tubectomy and IUDs) as the major contraceptives sponsored by the government, 
Table 1 Percentage distribution of married women aged 15-49 years using contraception by contraceptive method, according to selected characteristics, Tehran, Iran, 2014

\begin{tabular}{|c|c|c|c|c|c|c|c|}
\hline \multirow[b]{2}{*}{ Characteristic } & \multirow[b]{2}{*}{ Sterilisation } & \multirow[b]{2}{*}{ IUD* } & \multirow[b]{2}{*}{ Pillst } & \multirow[b]{2}{*}{ Condoms } & \multirow[b]{2}{*}{ Withdrawalł } & \multicolumn{2}{|l|}{ Total } \\
\hline & & & & & & $\%$ & $n$ \\
\hline \multicolumn{8}{|l|}{ Age (years) } \\
\hline $15-29$ & 0.6 & 9.2 & 14.8 & 33.8 & 41.6 & 100.0 & 488 \\
\hline $30-34$ & 5.4 & 9.5 & 8.3 & 36.9 & 39.9 & 100.0 & 632 \\
\hline $35-39$ & 12.8 & 11.5 & 9.2 & 26.6 & 39.9 & 100.0 & 541 \\
\hline $40-49$ & 34.0 & 7.9 & 5.6 & 9.6 & 42.9 & 100.0 & 800 \\
\hline \multicolumn{8}{|l|}{ Living children $(n) \S$} \\
\hline 0 & 0.6 & 1.3 & 12.1 & 46.6 & 39.3 & 100.0 & 313 \\
\hline 1 & 2.2 & 8.2 & 9.4 & 33.1 & 47.1 & 100.0 & 826 \\
\hline 2 & 15.3 & 12.6 & 9.1 & 18.1 & 44.9 & 100.0 & 952 \\
\hline $3+$ & 57.3 & 10.3 & 4.6 & 7.6 & 20.3 & 100.0 & 370 \\
\hline \multicolumn{8}{|l|}{ Fertility intentions } \\
\hline Want a(another) child & 0.0 & 5.3 & 10.8 & 41.6 & 42.5 & 100.0 & 604 \\
\hline Want no more children & 22.8 & 10.7 & 8.0 & 18.6 & 39.9 & & 1656 \\
\hline Unsure & 0.0 & 10.4 & 10.9 & 29.9 & 48.8 & 100.0 & 201 \\
\hline \multicolumn{8}{|l|}{ Schooling (years) } \\
\hline$<12$ & 31.6 & 11.7 & 9.9 & 12.2 & 34.7 & 100.0 & 658 \\
\hline 12 & 13.4 & 9.8 & 8.5 & 22.7 & 45.5 & 100.0 & 915 \\
\hline $13+$ & 5.3 & 7.1 & 8.7 & 37.3 & 41.7 & 100.0 & 888 \\
\hline \multicolumn{8}{|l|}{ Employment status } \\
\hline Unemployed & 17.5 & 9.7 & 9.4 & 23.9 & 39.6 & 100.0 & 2010 \\
\hline Employed & 6.0 & 7.8 & 6.9 & 30.8 & 48.6 & 100.0 & 451 \\
\hline \multicolumn{8}{|l|}{ Migration streams } \\
\hline Non-migrants & 13.0 & 8.3 & 8.3 & 28.2 & 42.1 & 100.0 & 1713 \\
\hline From other urban areas to the city of Tehran & 18.9 & 11.7 & 9.8 & 20.1 & 39.6 & 100.0 & 523 \\
\hline From rural areas to the city of Tehran & 24.9 & 11.6 & 12.0 & 13.8 & 37.8 & 100.0 & 225 \\
\hline \multicolumn{8}{|l|}{ Residential districts } \\
\hline Northern & 9.5 & 7.3 & 7.0 & 34.2 & 42.0 & 100.0 & 892 \\
\hline Central & 18.7 & 10.6 & 8.4 & 19.2 & 43.1 & 100.0 & 907 \\
\hline Southern & 18.6 & 10.4 & 12.4 & 21.1 & 37.5 & 100.0 & 662 \\
\hline Total & 15.4 & 9.3 & 8.9 & 25.2 & 41.2 & 100.0 & 2461 \\
\hline
\end{tabular}

Difference between distributions is significant at $p<0.001$.

${ }^{*}$ Includes seven women using Norplant ${ }^{\circledR}$.

tIncludes 18 women using the contraceptive injection.

\#Includes nine women using periodic abstinence.

$\S$ Consists of current pregnancies.

IUD, intrauterine device.

though $55 \%$ of women used male methods (condoms and withdrawal).

\section{Women affected by limiting the provision of family planning services}

Table 1 shows the characteristics of women using different contraceptive methods. As expected, sterilisation is used mostly by women who are in the late reproductive stage, have two or more children, want no more children, have fewer than 12 years of schooling, are unemployed and are migrants, and live in socioeconomically disadvantaged residential districts in the centre and south of Tehran. Women with similar characteristics also used the IUD, except that the IUD is mostly used by women who are in the mid- or early reproductive stages. In contrast, users of male methods, namely withdrawal and condoms, are mostly women who have fewer than three children, intend having a (another) child or are unsure about it, have a high school diploma or post-secondary education, are employed and non-migrants, and live in the more affluent northern residential districts.

Table 2 shows the net effect of women's characteristics on contraceptive method use. Of the women's characteristics, number of living children, fertility intentions, education, and residential district are significantly associated with the use of a long-acting method as opposed to a male contraceptive method. Specifically, women with fewer than three children are less likely to use long-acting methods than male 


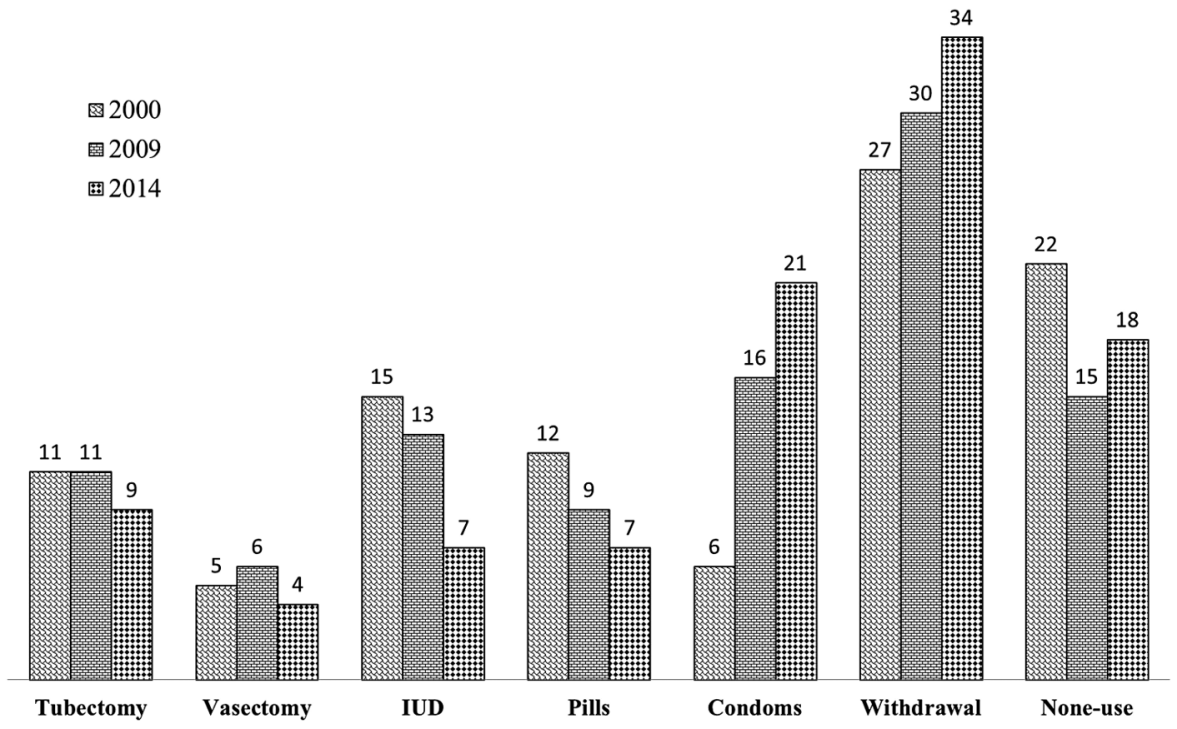

Figure 1 Trends of contraceptive use by method (in percentages) among married women aged 15-49 years residing in the city of Tehran, Iran: 2000-2014. Calculations are based on data taken from the 2000 Iran Demographic Health Survey, the 2009 Tehran Survey of Fertility, and the 2014 Tehran Survey of Fertility. ${ }^{26}$ In the 3 years examined, Norplant ${ }^{\circledR}$ and injection users (low frequencies of use) were respectively merged with intrauterine device and pill users. IUD, intrauterine device.

contraceptive methods, compared to those women with three or more children. Also, compared to women who are unsure of their fertility intentions, those who want no children in the future are 69\% more likely to use long-acting contraceptive methods than condoms or withdrawal. Also, women with schooling lower than high school diploma are $73 \%$ more likely to use long-acting methods than male contraceptive methods, compared with those women having post-secondary education.

\section{DISCUSSION}

In response to the persistent low fertility rate in Iran, conservative political and religious figures in legislative organisations have put forward ideas for eliminating or curbing the publicly-funded family planning programme of Iran with the intention of raising fertility rates. This study investigated what subgroups of the population were likely to be adversely affected if the provision of government-sponsored family planning services is limited. The most recent data from the 2014 Tehran Fertility Survey were utilised to fulfil this research objective.

This study found that the three long-acting contraceptive methods (vasectomy, tubectomy and IUD) subsidised by the government are mostly used by women who have a low level of education, live in poor neighbourhoods, have a large number of children, and want to stop childbearing. Therefore, these are the most vulnerable subgroups of the population if the publiclyfunded family planning services are curbed by the Parliament of Iran in the still under review Bill 446 banning sterilisation and abortion or any other similar restrictive bills and laws in the future. One drawback of such bills and laws will be a likely rise in unplanned births and therefore clandestine abortions, leading to maternal morbidity and mortality.

However, the good news is that the Ministry of Health of Iran is still delivering free contraceptive services to vulnerable women (except vasectomy to men), especially those who are living in deprived settings and who have a large number of children. As stated by the present Director General of Population, Family and School Health Department in the Ministry of Health of Iran, government-sponsored family planning services (except sterilisation) are currently delivered to women in rural and deprived areas by the existing network of health houses, to enhance maternal, infant and child health through appropriate birth spacing and child nutrition. ${ }^{18}$ Even under the newly developed reproductive health programme, which has replaced the old population control programme, the Ministry of Health will perform tubal ligation procedures (i.e. tubectomy) if it is approved by a district-level Tubal Ligation Committee in the Ministry of Health. Besides, if it is recognised that a pregnancy is likely to put a woman's life and her fetus at a temporary or permanent risk, she will be entitled to receive free contraceptive services as previously. However, if there are no risk factors with a woman's pregnancy, then she will have to purchase contraceptive methods from the private sector, including drugstores, according to the Technical Deputy of Population, Family and School Health Department in the Ministry of Health of Iran (personal e-mail communication with the author regarding recent developments in the free delivery of family planning services in Iran, 7 April 2015).

Although the recent pronatalist discourse and legislation regarding curbing family planning services and 
Table 2 Relative risk ratios (confidence intervals) of using long-acting contraceptive methods or pills versus condoms and withdrawal among married women aged 15-49 years using contraception by selected characteristics, Tehran, Iran, 2014

\begin{tabular}{|c|c|c|}
\hline Characteristic & $\begin{array}{l}\text { Long-acting } \\
\text { methodst vs } \\
\text { condoms/ } \\
\text { withdrawal }\end{array}$ & $\begin{array}{l}\text { Pills vs condoms/ } \\
\text { withdrawal }\end{array}$ \\
\hline \multicolumn{3}{|l|}{ Living children $(n)$} \\
\hline 0 & $0.04^{* * *}(0.02-0.09)$ & $1.64 \quad(0.72-3.72)$ \\
\hline 1 & $0.11 * * *(0.07-0.15)$ & $1.08 \quad(0.55-2.12)$ \\
\hline 2 & $0.23^{* * *}(0.17-0.30$ & $1.20 \quad(0.64-2.23)$ \\
\hline $3+($ Ref.) & 1.00 & 1.00 \\
\hline \multicolumn{3}{|l|}{ Fertility intentions } \\
\hline Want a(another) child & $0.65 \quad(0.36-1.18)$ & $0.79 \quad(0.46-1.38)$ \\
\hline Unsure (Ref.) & 1.00 & 1.00 \\
\hline Want no more children & $1.69 *(1.03-2.77)$ & $0.89 \quad(0.52-1.53)$ \\
\hline \multicolumn{3}{|l|}{ Schooling (years) } \\
\hline$<12$ & $1.73^{* *}(1.21-2.46)$ & $1.03 \quad(0.63-1.67)$ \\
\hline 12 & $1.14 \quad(0.84-1.55)$ & $0.84 \quad(0.57-1.25)$ \\
\hline $13+$ (Ref.) & 1.00 & 1.00 \\
\hline \multicolumn{3}{|l|}{ Employment status } \\
\hline Employed & $0.97 \quad(0.68-1.38)$ & $1.46 \quad(0.93-2.29)$ \\
\hline Unemployed (Ref.) & 1.00 & 1.00 \\
\hline \multicolumn{3}{|l|}{ Migration streams } \\
\hline Non-migrants & $1.09(0.75-1.59)$ & $0.58^{*}(0.34-0.96)$ \\
\hline $\begin{array}{l}\text { From other urban areas } \\
\text { to the city of Tehran }\end{array}$ & $1.34(0.90-2.00)$ & $0.74 \quad(0.43-1.26)$ \\
\hline $\begin{array}{l}\text { From rural areas to the } \\
\text { city of Tehran (Ref.) }\end{array}$ & 1.00 & 1.00 \\
\hline \multicolumn{3}{|l|}{ Residential districts } \\
\hline Northern & $0.75^{*}(0.56-0.99)$ & $0.52^{* * *}(0.34-0.78)$ \\
\hline Central & $1.01 \quad(0.78-1.31)$ & $0.69^{*}$ \\
\hline Southern (Ref.) & 1.00 & 1.00 \\
\hline
\end{tabular}

* Significant at $p \leq 0.05 ;{ }^{* *} p \leq 0.01 ;{ }^{* * *} p \leq 0.001$.

Ref., reference category.

tLong-acting methods include tubectomy, vasectomy, intrauterine device, Norplant ${ }^{\circledR}$ and contraceptive injection.

knowledge have been hastily proposed, the new reproductive health programme is promising as it appears to pay attention to women's reproductive health needs and rights. We should remember from history that the implementation of such shortsighted pronatalist policies in a few countries in the past can result in a temporary short-lived fertility rise along with a sharp rise in maternal morbidity and mortality, related to unintended pregnancies terminated by unsafe abortions. ${ }^{19}$ Also, though Iranian domestic pharmaceutical products, including contraceptives, are generally affordable for the vast majority of people, curbing the provision of family planning services differentially affects young and poor women who are not able to afford the cost of contraceptives, ${ }^{20}$ and elevates the existing unmet need for modern contraceptive methods. ${ }^{21} 22$ Limited access to legal means of contraception and abortion will not result in increased fertility because women are more likely to seek an unsafe, illegal abortion instead of continuing with an unwanted pregnancy. ${ }^{23}$ Besides its adverse health consequences, it is unlikely that curbing family planning services will lead to a long-lasting increase in the fertility rate. ${ }^{24}$ As argued by Demeny (p. 339), "increasing fertility through government intervention [will] likely be far more difficult and costly, politically as well as programmatically, than inducing a fertility decline". ${ }^{25}$ In fact, it is up to couples to decide upon their fertility.

Contributors The author exclusively designed the survey and analysed data, wrote and revised the manuscript.

Funding This study was supported by an Insight Development grant (430-2011-0464) received from the Social Science and Humanities Research Council of Canada. The 2014 Tehran Survey of Fertility was funded by National Population Studies and Comprehensive Management Institute, Ministry of Science, Research, and Technology (Tehran, Iran) and Nipissing University (Ontario, Canada). An earlier version of this article, which was based on the 2009 Tehran Survey of Fertility, was presented at the 2013 XXVII IUSSP International Population Conference in Busan, South Korea.

Competing interests None declared.

Ethics approval Nipissing University's Research Ethics Board. Provenance and peer review Not commissioned; externally peer reviewed.

Data sharing statement Any request for data sharing of the survey used in this paper will be considered by the author.

\section{REFERENCES}

1 Statistical Center of Iran. Population Indicators of Iran: 195696. Tehran, Iran: Statistical Center of Iran, 1999.

2 Erfani A, McQuillan K. Rapid fertility decline in Iran: analysis of intermediate variables. J Biosoc Sci 2008;40:459-478.

3 Statistical Center of Iran. Iran Statistical Yearbook 2011. Tehran, Iran: Statistical Center of Iran, 2011. http://salnameh. sci.org.ir [accessed 28 October 2015].

4 Hoodfar H, Assadpour S. The politics of population policy in the Islamic Republic of Iran. Stud Fam Plann 2000;31:19-34.

5 Roudi-Fahimi F. Iran is Reversing its Population Policy. Vol. 7. Middle East Program, Wilson Centre, Viewpoints, 2012:1-8.

6 Roudi-Fahimi F. Iran's Family Planning Program: Responding to a Nation's Needs. Washington, DC: Population Reference Bureau, 2002.

7 Erfani A, Yuksel-Kaptanoglu I. The use of withdrawal among birth limiters in Iran and Turkey. Stud Fam Plann 2012;43:21-32.

8 Erfani A. Fertility in Tehran City and Iran: rates, trends and differentials [in Persian]. Popul Stud 2013;1:87-107.

9 Khamenei SA. A speech among the public citizens of the city of Bujnord on September 9, 2012. http://www.leader.ir/langs/fa/ index.php?p=bayanat\&id=9952 [accessed 17 March 2015].

10 Yadegari MH. Family planning course removed from curriculum. Iranian Daily Hamshahri, 14 November 2012. http://hamshahrionline.ir/details/191283/Education/higher [accessed 23 April 2015].

11 Majles. Bill 446: Increasing Fertility Rate and Preventing the Decline of Population Growth Rate: 2nd revision dated 4 October 2014. http://parliran.ir/index.aspx? fkeyid=\&siteid= 1\&pageid $=4038$ [accessed 28 October 2015].

12 Dastjerdi M. Removal of population control program's budget. Fars News Agency, 1 August 2012. http://www.farsnews.com/ newstext.php?nn=13910511000015 [accessed 22 April 2015]. 
13 Majles. The First Five-Year Socio-Economic Development Program Law of the Islamic Republic of Iran. Tehran, Iran: Iranian Parliament, 2014. http://parliran.ir/index.aspx? fkeyid $=$ \&siteid $=1 \&$ pageid $=222[$ accessed 28 October 2015].

14 Fars News Agency. Seven years with the promises of President Ahmadinejad. Fars News Agency, 28 April 2012. http://www. farsnews.com/newstext.php?nn=13910209000434 [accessed 11 May 2015].

15 Dastjerdi M. Raising population cannot be imposed by force. Fars News Agency, 17 October 2012. http://www.farsnews.com/ newstext.php?nn=13910726000175 [accessed 22 April 2015].

16 Sangi A. Guidelines of the new population policy. Fars News Agency, 24 June 2013. http://www.farsnews.com/printable.php? $\mathrm{nn}=13920403000054$ [accessed 23 April 2015].

17 Khamenei A. Ayatollah Ali Khamenei on Iran's Population Policy. Popul Dev Rev 2014;40:573-575.

18 Motlagh ME, Eslami M. A round-table interview on population. Fars News Agency, 29 January 2014. http:/www.farsnews.com/ newstext.php?nn=13921109000105 [accessed 25 March 2015].

19 Horga M, Gerdts C, Potts M. The remarkable story of Romanian women's struggle to manage their fertility. J Fam Plann Reprod Health Care 2013;39:2-4.
20 Greenspan A. After the demographic transition: policy responses to low fertility in four Asian countries. Asia Pac Pop Policy 1994;30:1-4.

21 Hosseini H, Torabi F, Bagi B. Demand for long-acting and permanent contraceptive methods among Kurdish women in Mahabad, Iran. J Bioso Sci 2014;46:772-785.

22 Motlaq ME, Eslami M, Yazdanpanah M, et al. Contraceptive use and unmet need for family planning in Iran. Int J Gynaecol Obstet 2013;121:157-161.

23 Ahman EL, Shah IH. Contraceptive use, fertility, and unsafe abortion in developing countries. Eur J Contracept Reprod Health Care 2006;11:126-131.

24 Erfani A. Curbing family planning in Iran: an appraisal of Bill 446. J Fam Plann Reprod Health Care 2015;41:317-318.

25 Demeny P. Pronatalist policies in low-fertility countries: patterns, performance and prospects. In: Davis K, Bernstam MS, Ricardo-Campbell R (eds), Below-Replacement Fertility in Industrial Societies: Causes, Consequences, Policies. Population and Development Review (Supplement 12). 1986:335-358.

26 Erfani A. Tehran Survey of Fertility, 2014: Final Report [in Persian]. Tehran, Iran: National Population Studies and Comprehensive Management Institute: Ministry of Science, Research, and Technology, 2015. 